\author{
축열조용 복합 다층 단열재의 단열 성능 연구

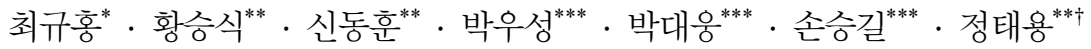 \\ *국민대학교 대학원 기계공학과, ${ }^{* *}$ 국민대학교 기계시스템공학부, ${ }^{* * *}$ 경동나비엔(주) 기술연구소 \\ (2014년 7월 18일 접수, 2014년 9월 11일 수정, 2014년 9월 15일 채택)
}

\title{
A Study on the Insulation Performance of Composite Multilayer Insulation by Applciation of Heat Storage Tank
}

Gyuhong Choi ${ }^{*}$. Seung Sik Hwang ${ }^{* *}$. Donghoon Shin ${ }^{* *}$. Woo Sung Park ${ }^{* *}$ Dae Woong Park ${ }^{* * *}$. Seung Kil Son ${ }^{* * *}$. Tae Yong Chung ${ }^{* *}$

"Dept. of Mechanical Engineering, Graduate School of Kookmin University,

${ }^{* *}$ Dept. of Mechanical Engineering, Kookmin University, ${ }^{* * *} \mathrm{KD}$ Navien Co., Ltd.

(Received 18 July 2014, Revised 11 September 2014, Accepted 15 September 2014)

요약

적층 단열재(multi-layer insulation, MLI)는 초전도 마그넷과 초전도 전력 케이블과 같은 초전도 응용기기의 냉각에 사용되는 저온유지장치(cryostat)에 외부 열침입을 차단하여 단열성능을 향상시키 기 위해 사용된다. 적층 단열재는 인공위성에 사용되는 단열재로 적층단열재를 구성하는 자재의 종류 와 적층층수 등에 따라 단열 성능이 변화한다.

본 연구에서는 적층 단열재의 원리를 이용한 축열조용 복합 다층 단열재(composite multilayer insulation, $\mathrm{CMI}$ )의 구성 재질 종류를 변경하고 적층 방식을 바꿈으로서 단열 성능이 바뀌는 것을 확인하였다.

실험은 KS C 9805의 방법을 이용하였으며, 복합 다층 단열재의 단열 성능 확인을 위해 동일한 조건의 축열조에 스티로폼을 적용하여 비교하였다. 또한, 실험 결과를 분석하기 위한 방법으로 기존 단열재에 대한 등가 두께를 비교하고 type별 $\mathrm{CMI}$ 의 열전도율을 구해 비교하였다.

그 결과 복합 다층 단열재의 등가 두께는 스티로폼 보다 작아 동일 두께인 경우 스티로폼 보다 단열성능이 더 우수함을 확인할 수 있었다. 또한, 복합 다층 단열재의 구성 소재 및 적층 방식에 따라 전도, 대류 및 복사와 관련된 값들의 변화가 총괄 열전달계수에 영향을 미치는 것을 확인할 수 있었다.

주요어 : 복합 다층 단열재, 등가 두께, 열전도율

Abstract - MLI(Multi-layer Insulation) is widely used to get highly insulating on cryogenic system in order to reduce heat loads. MLI for satellites thermal performance is changed by materials and laminated method.

In this study, a composite multilayer insulation by application of heat stroage tank performance were compared with materials and laminated to change the way.

Experimental methods of the KS C 9805 was used, the composite multilayer insulation and EPS was compared with the insulation performance. A method for analysis of experimental results is the equivalent thickness about $\mathrm{CMI}$ and the insulation performance were used to compare thermal conductance.

As a results, the equivalnet thickenss and the thermal conductance of the composite multilayer insulation were smaller than the EPS and the thermal performance are more excellent. In addition, the configuration of

\footnotetext{
${ }^{\dagger}$ To whom corresponding should be addressed.

Dept. of Mechanical Engineering, Kookmin University

Tel : 02-910-4674 E-mail : tychung@kookmin.ac.kr
} 
the composite multilayer insulation materials and laminated method varies depending on the overall heat transfer coefficient was confirmed.

Key words : Composite multilayer insulation, overall heat transfer coefficient, dimensionless temperature ratio

\section{1. 서 론}

적층 단열재(multi-layer insulation, $\mathrm{MLI}$ )는 초전도 마그넷과 초전도 전력 케이블과 같은 초전도 응용기 기의 냉각에 사용되는 저온유지장치(cryostat)에 외부 열침입을 차단하여 단열성능을 향상시키기 위해 사용 한다. 적층 단열재는 적층 단열재 자재의 종류와 적 층 층수 등에 따라 cryostat의 단열 성능이 변화한다 ${ }^{1]}$.

적층 단열재는 인공위성에 사용되는 단열재로 여 러 종류의 소재를 적층하여 원하는 조건의 단열 상태 를 만든 단열재로 진공인 상태에서 우주 공간에서의 열제어 방법으로 적용하고 있다 ${ }^{2]}$. 복합 다층 단열재 (composite multilayer insulation, $\mathrm{MLI}$ )는 적층 단열 재의 원리를 이용하여 필름에 국한되지 않은 여러 종 류의 소재를 적층한 단열재를 의미한다.

본 연구는 복합 다층 단열재를 제작함에 있어 그 사용 재질의 종류를 변경하고 구성 방식을 바꿈으로

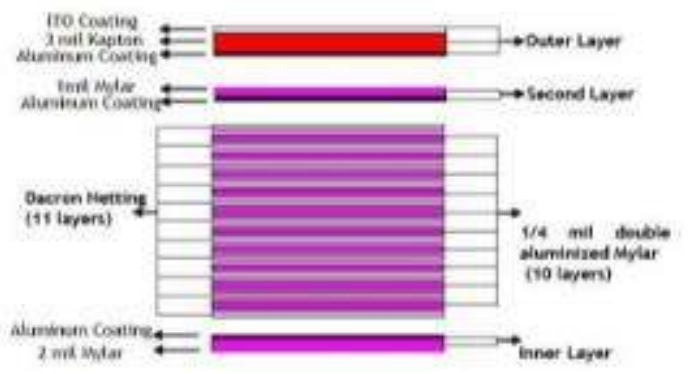

Fig. 1. Construction of MLI for Satellite ${ }^{2]}$
서 대기압 상온 조건에서 축열조용 복합 다층 단열재 의 단열 성능을 실험하고 결과를 분석하였다.

\section{2. 실험}

\section{2-1. 복합 다층 단열재의 형태}

연구를 위해 제작한 복합 다층 단열재는 그림 1 과 같은 구조의 다층박막 단열재를 그림 2 와 같은 형태 로 변형한 것이다. 구성은 축열조 측과 외부 공기측 의 외부 소재, 전도 차단층 또는 복사차단층 그리고 각각의 소재 사이에는 전도 손실을 최소화하기 위해 메시를 사용하였다.

표 1 에는 6 종류의 복합 다층 단열재의 구성과 적 층 방식을 나타내었다. 표 1 에 언급한 공기층은 축열 조 측 소재의 아래 부분에 두고, 전도 차단층과 복사 차단층은 복합 다층 단열재의 내부에 들어가는 소재 를 바꿔가면서 제작한 것이다. 따라서 복합 다층 단 열재에 사용된 자재의 종류 및 수량에 따라 단열재의 적용 두께와 그 형태가 달라지게 되었다.

표 1 에서 복사차단 층은 플라스틱 필름류에 알루 미늄을 증착한 것을 사용한 것이며, 전도차단 층은 공기의 이동유무에 의해 구분된다. 1 종 전도차단 층 은 공기가 움직이지 못하는 형태를 가지며, 2종 전도 차단 층은 공기가 움직이는 형태를 가진다.

\section{2-1. 실험장치}

복합 다층 단열재의 실험을 위한 실험장치로 온도

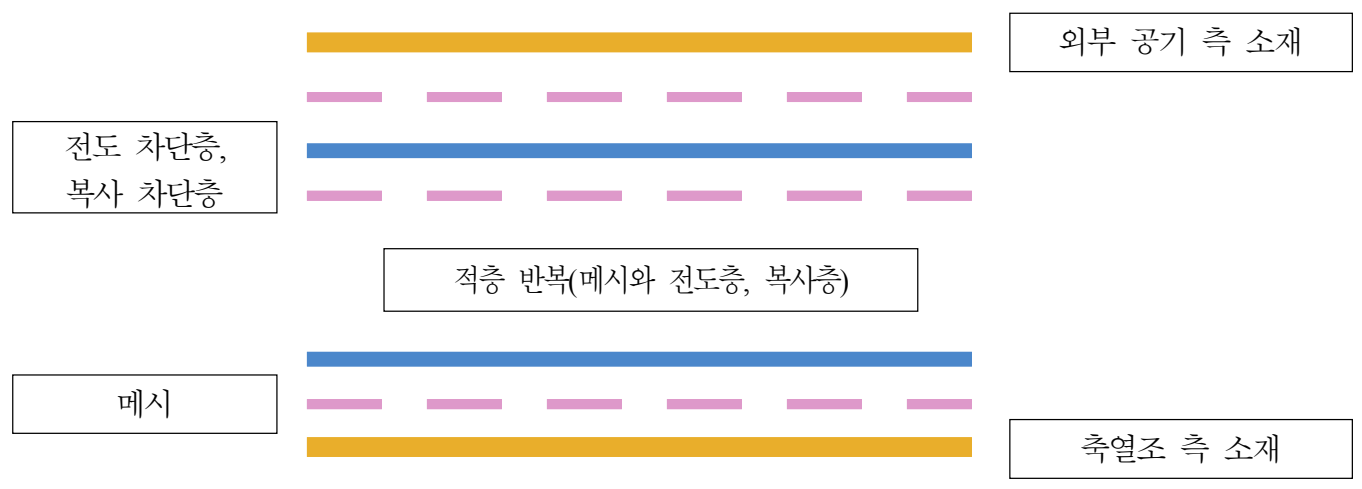

Fig. 2. Construction of composite multilayer insulation 
Table 1. Composite multilayer insulation of application type

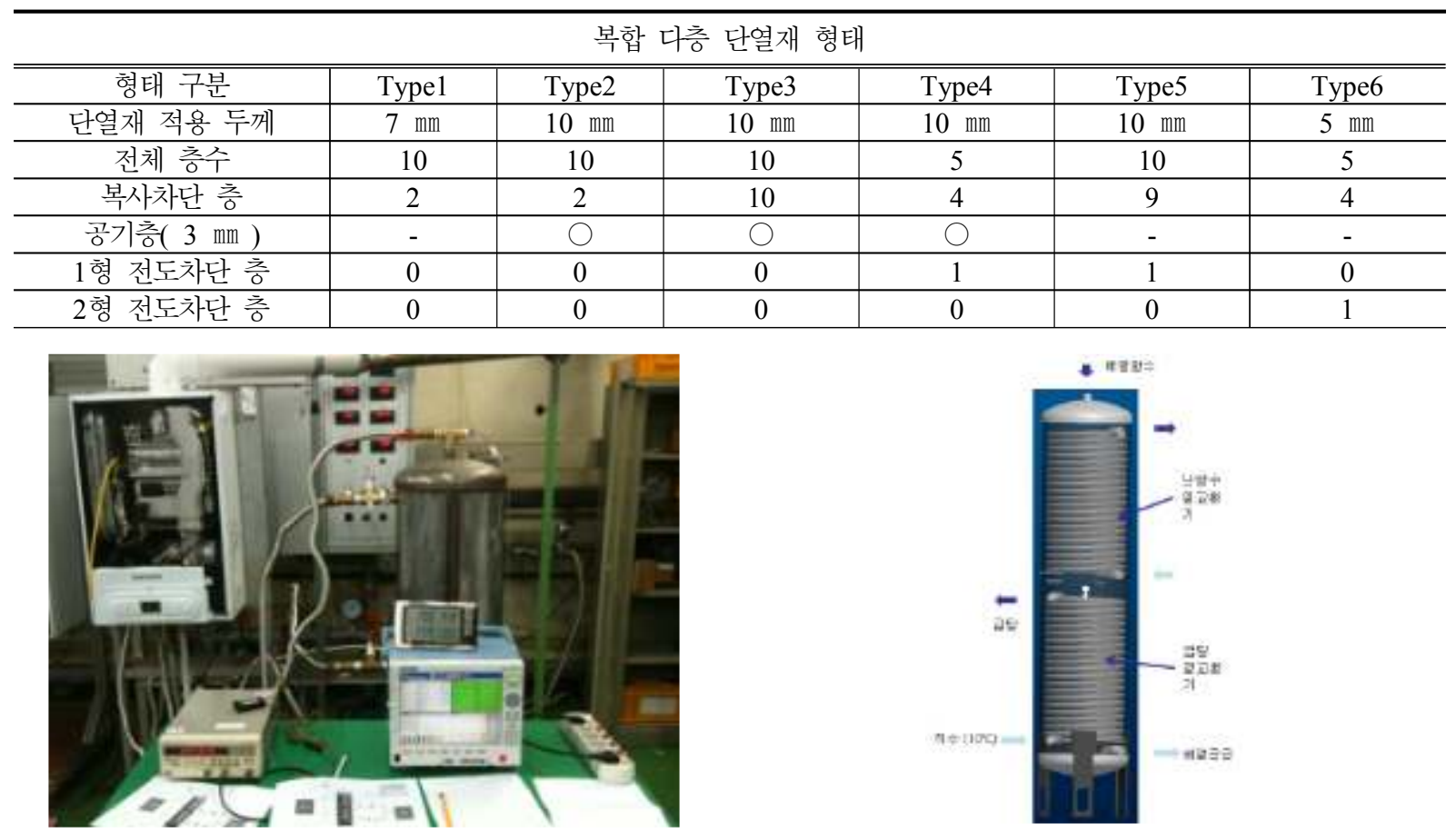

Fig. 3 Experimental Equipment

Table 2. Specification of Heat Storage Tank

\begin{tabular}{|c|c|c|c|}
\hline 부품명 & 구 분 & 사 양 & 재질 \\
\hline \multirow{2}{*}{$\begin{array}{c}\text { 난방수 } \\
\text { 열교환기 }\end{array}$} & $\begin{array}{c}\text { 배관 } \\
\text { 사이즈 }\end{array}$ & $\varnothing 270 \times \mathrm{p} 25 \times \mathrm{t} 20$ & \multirow{2}{*}{$\begin{array}{l}\text { SUS304, } \\
\text { C1220-OL }\end{array}$} \\
\hline & 배관 경 & $\varnothing 15.88 \times \mathrm{t} 0.7$ & \\
\hline \multirow{2}{*}{$\begin{array}{c}\text { 급탕 } \\
\text { 열교환기 }\end{array}$} & $\begin{array}{c}\text { 배관 } \\
\text { 사이즈 }\end{array}$ & $\varnothing 270 \times \mathrm{p} 25 \times \mathrm{t} 19$ & \multirow{2}{*}{$\begin{array}{c}\text { SUS304, } \\
\text { C1220-OL }\end{array}$} \\
\hline & 배관 경 & $\varnothing 15.88 \times \mathrm{t} 0.7$ & \\
\hline $\begin{array}{l}\text { 배열 } \\
\text { 펌프 } \\
\end{array}$ & $\begin{array}{c}\text { 유량 } \\
\text { 데이터 }\end{array}$ & 20 LPM & \\
\hline \multirow{4}{*}{ 온수탱크 } & 규격 & 압력탱크 & \multirow{4}{*}{$\begin{array}{c}\text { 경판 : } \\
\text { SUS316L } \\
\text { 몸체 : } \\
\text { SUS436L }\end{array}$} \\
\hline & TYPE & 개방형 & \\
\hline & 용량 & $90 \mathrm{~L}$ & \\
\hline & 사이즈 & $\begin{array}{c}\varnothing 313.5 \mathrm{x} \\
1,320 \text { (몸체) }\end{array}$ & \\
\hline
\end{tabular}

측정을 위한 계측기는 YOKOGAWA 2000을 사용하 였다. 실험장치는 그림 3 , 축열조의 사양은 표 2 , 축 열조의 내부는 그림 4 와 같다.

\section{2-2. 실험방법}

축열조의 보온 실험은 KS C 9805의 보온 효율 실 험방법을 이용하였달. 먼저 보일러가 $7 \mathrm{~kW}$ 로 일정하
Fig. 4 Internal Geometry of Heat Storage Tank

게 열량을 공급하여 물을 가열하고 축열조 내부 물의 온도를 $60^{\circ} \mathrm{C}$ 까지 올렸다. 이 후 강제적인 냉각 효과 가 없는 상태로 13 시간 동안 두어 온도 하락폭을 기 록하였다.

실험 결과를 비교하기 위한 실험 비교군으로 기존 축열조용 단열재로 사용되던 스티로폼 $50 \mathrm{~mm}$ 를 이용 하였으며, 그림 5에 그 예를 나타내었다.

\section{2-3. 실험결과 분석 방법}

복합 다층 단열재는 그림 2 와 같이 여러 겹의 소재와 메시를 차례로 적층하여 구성하였다. 따라서 복합 다층 단열재를 통한 열전달 경로는 복사 및 접촉에 의한 전 도 현상이며, 대기압 하에서는 복합 다층 단열재 내부에 존재하는 기체에 의한 열전달도 발생한다. 그러나 적용 된 재질이나, 밀도 및 온도의 변수로 복합 다층 단열재 의 열전도성을 엄밀히 정의하고 적용하는 것은 어렵달.

\section{2-3-1. 열전달 개념}

그림 6에서 두 면 사이의 체적에 대하여 에너지 출 입의 평형식을 세우면 식 (1)과 같다.

$$
\sum \dot{Q}_{T}=\dot{Q}_{\text {cond }}-\dot{Q}_{\text {conv }}-\dot{Q}_{\text {rad }}=0
$$




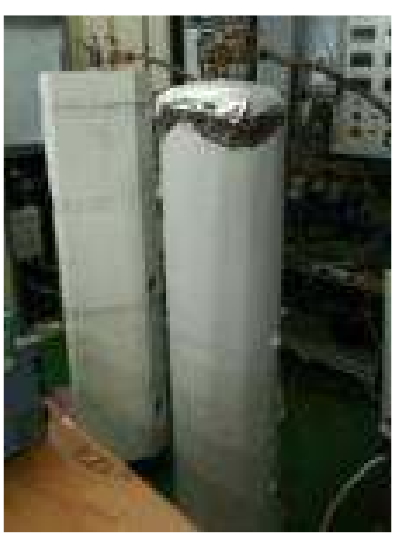

Fig. 5 Type 1 CMI and EPS installation heat storage tank

유한한 벽체를 통과하는 일차원 열전도 문제는 푸 리에의 열전도법칙과 적정한 경계조건으로 구하면 식 (2)와 같다.

$$
\dot{Q}_{\text {cond }}=k_{i} A\left(T_{1}-T_{2}\right) / L_{e}
$$

표면을 통과하는 열전달율 $\dot{Q}_{s}$ 는 대류 및 복사열전 달이 병행하여 발생하는 현상이므로 다음과 같이 된 다.

$$
\begin{aligned}
\dot{Q}_{s} & =\dot{Q_{c o m v}}+\dot{Q}_{r a d} \\
& =\left(h_{\text {conv }}+h_{r a d}\right) A\left(T_{s}-T_{a}\right)=h_{s} A\left(T_{s}-T_{a}\right)
\end{aligned}
$$

식 (1)에 식 (2)와 식 (3)을 대입하여 에너지 평형 식을 정리하여 보온재의 등가 두께로 정리하면 요구 되는 표면 온도가 주어진 기계설비의 보온 시스템에 서의 등가 두께를 식 (4)와 같이 구할 수 있다.

$$
L_{e}=\left(\frac{k_{i}}{h_{s}}\right)\left[\frac{\left(T_{1}-T_{2}\right)}{\left(T_{2}-T_{a}\right)}\right]
$$

2-3-2. 실험 결과 및 분석

주어진 온도에 대한 온도 강하에 필요한 시간은 식 (5)와 같고, 이 때의 손실 열량은 식 (6)과 같다. ${ }^{6]}$

$$
t_{v}=\frac{\left(T_{f i}-T_{a}\right)\left(m c_{p}\right) \ln \frac{\left(T_{f i}-T_{a}\right)}{\left(T_{f t}-T_{a}\right)}}{3.6 q A}
$$

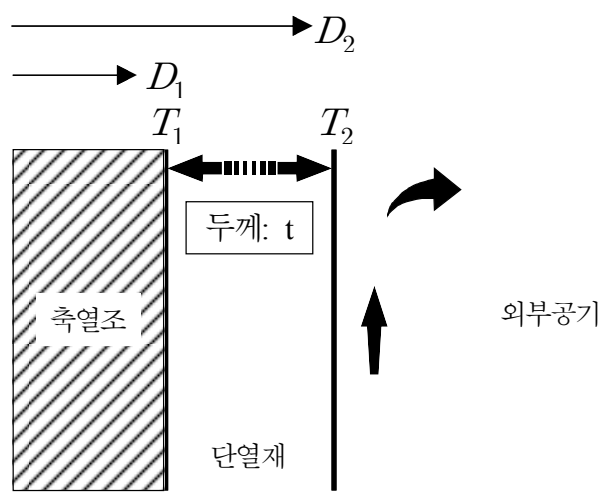

Fig. 6 Heat transfer concept of heat storage tank

$$
q=\frac{\left(T_{f i}-T_{a}\right)}{\frac{d}{k_{i}}+\frac{1}{h_{s}}}
$$

식 (5)를 $q$ 에 대해서 정리한 후 식 (6)에 대입하고 식 (6)을 $k_{i}$ 에 대해서 정리하면 식 (7)이 된다.

$$
k_{i}=d \frac{1}{\frac{T_{f i}-T_{a}}{q}-\frac{1}{h_{s}}}
$$

\section{3. 실험 결과 및 검토}

\section{3-1. 실험 결과}

복합 다층 단열재의 실험 결과의 예를 그림 7에 나 타내었으며, 이 때 발생한 열손실을 계산하여 표 3에 정리하였다. 표 3 을 보면 대기 온도가 낮아질수록 더 많은 손실 열량이 생기는 것을 확인할 수 있다.

3-2. 실험 결과 검토

냉각 시간과 단열재의 온도를 이용하여 $\mathrm{CMI}$ 의 EPS 등가 두께를 계산한 결과를 표 4에 나타내었다.

표 4를 보면 구성이 다른 각 Type에 따라 EPS 등 가 두께도 달라졌으며, $\mathrm{CMI}$ 두께 대비 등가 두께의 비도 $0.143 \sim 0.833$ 의 범위인 것을 알 수 있다.

표 5는 식 (7)을 이용하여 구한 복합 다층 단열재 의 열전도율을 정리한 것이다. Type 2 를 제외한 나머 지 Type은 열전도율이 비교 대상인 EPS의 열전도율 


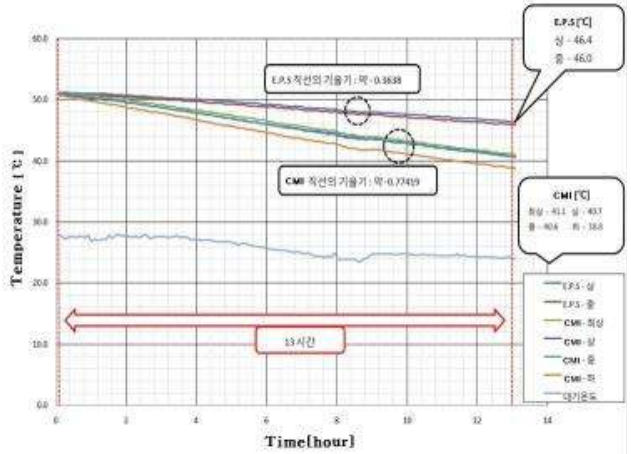

(a)

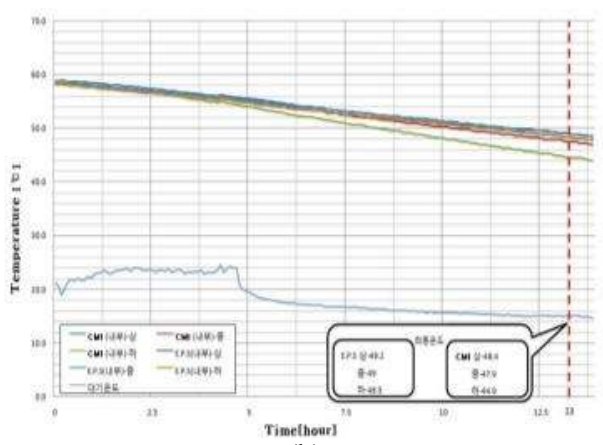

(b)

Fig. 7 Result of heat storage tank insulation test

Table 3. Result of heat storage tank insulation test

\begin{tabular}{|c|c|c|c|c|c|}
\hline Serial No. & Kind of insulation & $\begin{array}{c}\text { Start temp. } \\
{\left[{ }^{\circ} \mathrm{C}\right]} \\
\end{array}$ & $\begin{array}{c}\text { Finish temp. } \\
{\left[{ }^{\circ} \mathrm{C}\right]} \\
\end{array}$ & $\begin{array}{c}\text { Heat loss } \\
{[\mathrm{W}]}\end{array}$ & $\begin{array}{c}\text { Atmospheric temp. } \\
{\left[{ }^{\circ} \mathrm{C}\right]}\end{array}$ \\
\hline \multirow{2}{*}{1} & EPS & 51.1 & 46.2 & 495.9 & \multirow{2}{*}{25.8} \\
\hline & Type 1 CMI & 50.4 & 40.3 & $1,051.7$ & \\
\hline \multirow{2}{*}{2} & EPS & 50.4 & 45.5 & 512.8 & \multirow{2}{*}{26.6} \\
\hline & Type 1 CMI & 50.5 & 40.6 & $1,041.3$ & \\
\hline \multirow{2}{*}{3} & EPS & 60.0 & 52.9 & 735.7 & \multirow{2}{*}{25.1} \\
\hline & Type 1 CMI & 60.0 & 47.6 & $1,297.7$ & \\
\hline \multirow{2}{*}{4} & EPS & 58.8 & 51.0 & 816.3 & \multirow{2}{*}{18.7} \\
\hline & Type 1 CMI & 58.9 & 46.0 & $1,350.0$ & \\
\hline \multirow{2}{*}{5} & EPS & 60.2 & 52.2 & 837.2 & \multirow{2}{*}{19.3} \\
\hline & Type 1 CMI & 60.4 & 47.4 & $1,360.5$ & \\
\hline \multirow{2}{*}{6} & EPS & 58.4 & 48.9 & 994.2 & \multirow{2}{*}{18.5} \\
\hline & Type 1 CMI & 58.7 & 47.1 & $1,214.0$ & \\
\hline
\end{tabular}

Table 4. EPS equivalent thickness of CMI

\begin{tabular}{|c|c|c|c|c|c|}
\hline Type & $\begin{array}{c}\text { Experiment application } \\
\text { thickness }[\mathrm{m}]\end{array}$ & $\begin{array}{c}\text { Outdoor } \\
\text { temperature }\left[{ }^{\circ} \mathrm{C}\right]\end{array}$ & $\begin{array}{c}\text { CMI thickenss } \\
{[\mathrm{m}]} \\
\end{array}$ & $\begin{array}{c}\text { Equivalent } \\
\text { thickness }[\mathrm{m}]\end{array}$ & Ratio \\
\hline Type 1 & \multirow[t]{6}{*}{ " } & 25.8 & 0.007 & 0.022 & 0.318 \\
\hline Type 2 & & 26.6 & 0.01 & 0.016 & 0.625 \\
\hline Type 3 & & 25.1 & 0.01 & 0.012 & 0.833 \\
\hline Type 4 & & 18.7 & 0.01 & 0.014 & 0.714 \\
\hline Type 5 & & 19.3 & 0.01 & 0.012 & 0.833 \\
\hline Type 6 & & 18.5 & 0.005 & 0.035 & 0.143 \\
\hline
\end{tabular}

Table 5. CMI thermal conductance of each type

\begin{tabular}{c|c|c|c|c|c|c}
\hline CMI & $\begin{array}{c}\text { Type } \\
1\end{array}$ & $\begin{array}{c}\text { Type } \\
2\end{array}$ & $\begin{array}{c}\text { Type } \\
3\end{array}$ & $\begin{array}{c}\text { Type } \\
4\end{array}$ & $\begin{array}{c}\text { Type } \\
5\end{array}$ & $\begin{array}{c}\text { Type } \\
6\end{array}$ \\
\hline \hline $\begin{array}{c}\text { Thermal } \\
\text { conductivity } \\
{[\mathrm{W} / \mathrm{m} \cdot \mathrm{K}]}\end{array}$ & $\begin{array}{c}0.03 \\
2\end{array}$ & $\begin{array}{c}0.03 \\
5\end{array}$ & $\begin{array}{c}0.02 \\
4\end{array}$ & $\begin{array}{c}0.02 \\
1\end{array}$ & $\begin{array}{c}0.02 \\
9\end{array}$ & $\begin{array}{c}0.01 \\
3\end{array}$ \\
\hline
\end{tabular}

$0.035 \mathrm{~W} / \mathrm{m} \cdot \mathrm{K}$ 보다 더 작음을 알 수 있다. 특히 type 6은 EPS 대비 약 $1 / 3$ 수준임을 알 수 있다.

표 4와 표 5의 결과를 종합해볼 때 Type 6의 경우 계산된 열전도율은 EPS 대비 $1 / 3$ 수준이지만, 등가두
께는 $1 / 7$ 수준이 된다. 이는 복합 다층 단열재가 일반 단열재와는 달리 전도에 의한 열손실을 줄이는 기능 이외에 복사에 의한 열손실을 방지하는 기능을 가졌 음을 보여준다 할 수 있다.

\section{4. 결 론}

본 연구에서 복합 다층 단열재의 구성 소재 및 적 층방식을 달리하여 제작한 후 축열조에 적용하여 보 
온 성능을 실험하였다. 비교 단열재는 두께 $50 \mathrm{~mm}$ 의 EPS로 하였으며 단열 성능을 비교한 결과는 다음과 같다.

(1) 복합 다층 단열재는 EPS 대비 등가 두께의 비 율이 $0.143 \sim 0.833$ 범위로 얇은 두께이지만 기존 EPS 보다 단열 성능이 더 뛰어난 것을 확인하였으며, 동일한 단열효과를 나타내는 두께가 스티로폼보다 얇아짐을 알 수 있다.

(2) 복합 다층 단열재는 스티로폼의 열전도율이 $0.035 \mathrm{~W} / \mathrm{m} \cdot \mathrm{K}$ 인데 반해 구성 방식에 따라 $0.013 \sim 0.035 \mathrm{~W} / \mathrm{m} \cdot \mathrm{K}$ 의 값을 가졌다. 이는 복합 다층 단열재의 구성 방식을 바꾸어 줌으 로서 열전도율이 더 낮은 좋은 단열재의 제작 이 가능함을 확인한 것이다.

(3) 이와 같은 결과를 토대로 볼 때 복합 다층 단 열재의 구성 소재 및 적층 방식에 따라 전도, 대류 및 복사와 관련된 값들의 변화가 생겨 열전도율과 등가 두께가 달라질 수 있음을 확 인하였다.

(4) 복합 다층 단열재의 단열 성능에 대한 경향을 파악하고 성능을 예측하기 위한 이론적인 연 구가 필요하다고 사료된다.

\section{후 기}

본 연구는 국민대학교 교내연구 지원사업(2014 년)과 산업통상자원부의 재원으로 한국에너지기술평 가원(KETEP) 에너지인력양성사업(20134040200580) 의 지원을 받아 수행되었으며, 이에 감사드립니다.

\section{References}

1. 정원묵, 김동락, 양형석, 이병섭, 황시돌, 적층단 열재의 단열성능 실험적 고찰, 대한기계학회 2005년도 춘계학술대회 논문집, 2005, 2524-2528

2. 현범석, 김희경, 최준민. 다층박막단열재 열해석 방법 비교 연구, 대학기계학회 2003년도 추계 학술대회 논문집, 2003, 290-295
3. 산업통상자원부 기술표준원장, 가정용 축열식 전기보일러 및 저탕식 전기 온수기, $\mathrm{KS} \mathrm{C}$ 9805, 2013

4. Gilmore, D., Satellite Thermal Control Handbook, Aerospace Corporation Press, E1 Segundo, California, 1994

5. 정태용, 박복춘, 박형구, 부준홍, 서정세, 열전달, 교보문고, 2007

6. 강병하, 피창헌, 김석현. 단열재가 부착된 수직 벽 표면의 온도제어 해석, 설비공학논문집 제 24 권 4호, 2012, 323-329

7. 산업통상자원부 기술표준원장, 보온 보랭 공사 의 시공 표준, KS F 2803, 2013 